\title{
Development of High Torque and High Power Density Hybrid Excitation Flux Switching Motor for Traction Drive in Hybrid Electric Vehicles
}

\author{
Erwan Sulaiman ${ }^{1,2 *}$, Takashi Kosaka ${ }^{2}$ \\ ${ }^{1}$ MyEV, Department of Electrical Power Engineering, University Tun Hussein Onn Malaysia, Johor, Malaysia \\ ${ }^{2}$ Department of Electrical \& Computer Science Engineering, Nagoya Institute of Technology, Nagoya, Japan \\ Email: *erwan@uthm.edu.my
}

Received February 15, 2012; revised January 2, 2013; accepted January 9, 2013

Copyright (C) 2013 Erwan Sulaiman, Takashi Kosaka. This is an open access article distributed under the Creative Commons Attribution License, which permits unrestricted use, distribution, and reproduction in any medium, provided the original work is properly cited.

\begin{abstract}
This paper presents design feasibility study and development of a new hybrid excitation flux switching motor (HEFSM) as a contender for traction drives in hybrid electric vehicles (HEVs). Initially, the motor general construction, the basic working principle and the design concept of the proposed HEFSM are outlined. Then, the initial drive performances of the proposed HEFSM are evaluated based on 2D-FEA, in which the design restrictions, specifications and target performances are similar with conventional interior permanent magnet synchronous motor (IPMSM) used in HEV. Since the initial results fail to achieve the target performances, deterministic design optimization approach is used to treat several design parameters. After several cycles of optimization, the proposed motor makes it possible to obtain the target torque and power of $333 \mathrm{Nm}$ and $123 \mathrm{~kW}$, respectively. In addition, due to definite advantage of robust rotor structure of HEFSM, rotor mechanical stress prediction at maximum speed of $12,400 \mathrm{r} / \mathrm{min}$ is much lower than the mechanical stress in conventional IPMSM. Finally, the maximum torque and power density of the final design HEFSM are approximately $11.41 \mathrm{Nm} / \mathrm{kg}$ and $5.55 \mathrm{~kW} / \mathrm{kg}$, respectively, which is $19.98 \%$ and $58.12 \%$ more than the torque and power density in existing IPMSM for Lexus RX400h.
\end{abstract}

Keywords: Hybrid Excitation Flux Switching Machine (HEFSM); Field Excitation Coil (FEC); Permanent Magnet (PM); Hybrid Electric Vehicle (HEV)

\section{Introduction}

Hybrid excitation machine (HEM) which consists of permanent magnet (PM) and field excitation coil (FEC) as their combined flux sources, has several unique features that can be applied in HEV drive system. In general HEM can be classified into four categories based on the location of PM and FEC such as 1) both PM and FEC are located at rotor side [1-3], 2) the PM is in the rotor while the FEC is in the stator [4], 3) the PM is in the rotor while the FEC is in the machine end [5,6], and 4) both PM and FEC are located in the stator [7-9]. All HEMs mentioned in the first three consist of a PM in the rotor and can be categorized as "hybrid rotor-PM with FEC machines" while the final machine can be referred as "hybrid stator-PM with FEC machines". Based on its principles of operation, in which the fluxes sources are

"Corresponding author. generated in stator side and moved into the rotor, the fourth machine is also known as "hybrid excitation flux switching machine" (HEFSM) which is getting more popular recently $[10,11]$. With all active parts located on the stator, HEFSM has the advantages of 1) robust rotor structure which is becoming more suitable to be applied for high-speed drive applications, 2) due to the fact that the all major heats are accumulated in stator part, a simple cooling system can be applied compared with a complex water jacket system used in IPMSM for Lexus RX400h, and 3) the additional FEC can be used to control flux with variable flux capabilities.

Various combinations of stator slot and rotor pole for HEFSM have been developed for high speed applications. For example, 12Slot-10Pole HEFSM has been proposed such as in $[12,13]$. However, the machine in [12] has a separated PM and C-type stator core that makes it difficult to manufacture, and the design is not yet optimized 
for HEV applications while the machine in [13] has a limitation of torque and power production in high current density condition. This is due to insufficient stator yoke width between FEC and armature coil slots resulting in magnetic saturation and negative torque production. To reduce the supply frequency of inverter, 6Slot-5Pole HEFSM has been proposed by the authors. Although the proposed machine has met the target performances, the problem of unbalanced pulling force due to odd number of poles is difficult to overcome [14]. In addition, some researchers have proposed 6Slot-8Pole machines but these types of machines have problems of high torque ripple and back-emf waveforms, which are usual concerns for this type of eight pole machine $[15,16]$.

In this paper, design feasibility and optimization studies are conducted to 12Slot-10Pole HEFSM in effort to achieve the target performances for HEV applications. Figure 1 illustrates the cross-sectional view of the main machine part of the initial HEFSM. The motor is composed of $12 \mathrm{PMs}$ and $12 \mathrm{FECs}$ distributed uniformly in the midst of each armature coil while the three-phase armature coils are accommodated in the 12 slots for each $1 / 4$ stator body periodically. In this motor, the PMs and FECs produce six north poles interspersed between six south poles. The flux paths caused by both PM and mmf of FEC under open circuit condition are demonstrated in Figure 2. The term, "flux switching", is created based on the changes in polarity of each flux in each stator tooth, depending on the motion of the rotor. When the rotor rotates, the fluxes generated by PM and FEC link with the armature coil flux alternately. For the rotor rotation through $1 / 10$ of a revolution, the flux linkage of the armature coil has one periodic cycle and thus, the frequency of back-emf induced in the armature coil becomes ten times of the mechanical rotational frequency.

\section{Design Requirements, Restrictions and Specifications for HEV Applications}

The design requirements, restrictions and specifications of the proposed HEFSM for HEV applications are similar with IPMSM for Lexus RX400h listed in Table 1 [17]. The electrical restrictions related with the inverter such as maximum $650 \mathrm{~V}$ DC bus voltage and maximum $360 \mathrm{~V}$ inverter current are set. The limit of the armature coil current density, $\mathrm{J}_{\mathrm{a}}$ and the FEC current density, $\mathrm{J}_{\mathrm{e}}$ is set to $30 \mathrm{~A}_{\mathrm{rms}} / \mathrm{mm}^{2}$ and $30 \mathrm{~A} / \mathrm{mm}^{2}$, respectively. The weight of the PM is $1.1 \mathrm{~kg}$ similar with PM volume in IPMSM. The target torque of $333 \mathrm{Nm}$ with reduction gear ration of 2.478 is set, hence, realizing the maximum axle torque via reduction gear of $825 \mathrm{Nm}$. The maximum operating speed is set to $12,400 \mathrm{r} / \mathrm{min}$ and the target power is set to be more than $123 \mathrm{~kW}$. As the proposed HEFSM consists of very simple structure with concentrated winding in all coils, the target motor weight to be

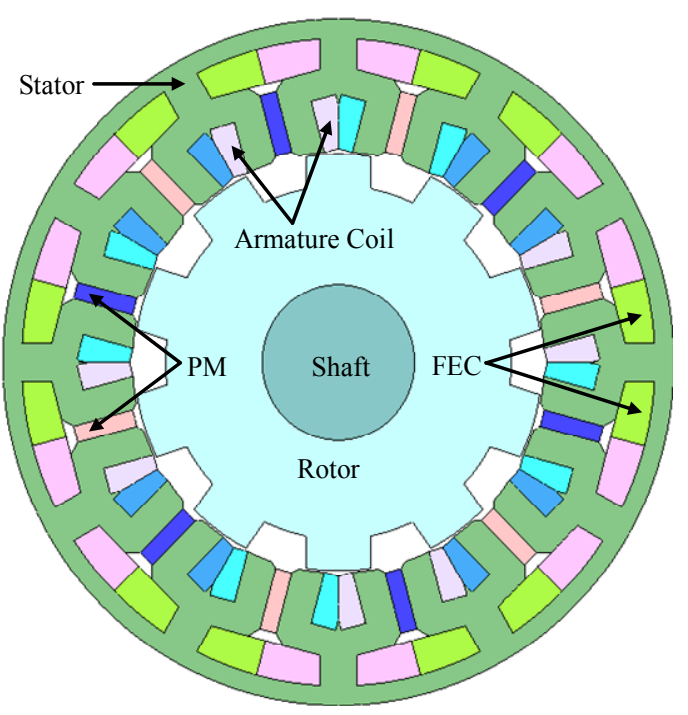

Figure 1. 12Slot-10Pole HEFSM.

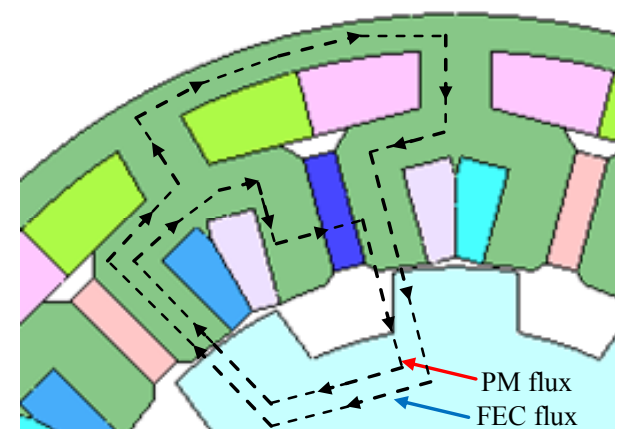

Figure 2. Flux paths of PM and FEC in 12Slot-10Pole HEFSM.

Table 1. HEFSM design restrictions and specifications.

\begin{tabular}{ccc}
\hline Items & IPMSM & HEFSM \\
\hline Maximum DC-bus voltage inverter $(\mathrm{V})$ & 650 & 650 \\
Maximum inverter current $\left(\mathrm{A}_{\mathrm{rms}}\right)$ & 360 & 360 \\
Maximum $\mathrm{J}_{\mathrm{a}}\left(\mathrm{A}_{\mathrm{rms}} / \mathrm{mm}^{2}\right)^{\mathrm{a}}$ & 31 & 30 \\
Maximum $\mathrm{J}_{\mathrm{e}}\left(\mathrm{A} / \mathrm{mm}^{2}\right)^{\mathrm{b}}$ & $\mathrm{NA}$ & 30 \\
Stator outer diameter $(\mathrm{mm})$ & 264 & 264 \\
Motor stack length $(\mathrm{mm})$ & 70 & 70 \\
Shaft radius $(\mathrm{mm})$ & 30 & 30 \\
Air gap length $(\mathrm{mm})$ & 0.8 & 0.8 \\
PM weight $(\mathrm{kg})$ & 1.1 & 1.1 \\
Maximum speed $(\mathrm{r} / \mathrm{min})$ & 12,400 & 12,400 \\
Maximum torque $(\mathrm{Nm})$ & 333 & 333 \\
Reduction gear ratio & 2.478 & 2.478 \\
Power density $(\mathrm{kW} / \mathrm{kg})$ & 825 & 825 \\
Maximum power $(\mathrm{kW})$ & 123 & $>123$ \\
Max. axle torque via reduction gear $(\mathrm{Nm})$ & 3.5 & $>3.5$ \\
\hline
\end{tabular}

$\mathrm{J}_{\mathrm{a}}=$ current density in armature coil; $\mathrm{J}_{\mathrm{e}}=$ current density in FEC. 
designed is set to be less than $35 \mathrm{~kg}$, resulting in that the proposed machine promises to achieve the maximum power density of more than $3.5 \mathrm{~kW} / \mathrm{kg}$. Commercial FEA package, JMAG-Studio ver.10.0, released by Japanese Research Institute (JRI) is used as 2D-FEA solver in this design.

\section{Initial Performances of the Proposed HEFSM Based on 2D-FEA}

Initially, performances of the proposed HEFSM in open circuit condition such as back-emf and cogging torque are analyzed as shown in Figures 3 and 4. In Figure 3, the amplitude of the fundamental component in which the induced voltage is generated from the flux of PM only is $123.6 \mathrm{~V}$. The back-emf is slightly sinusoidal which results a small amount of cogging torque of approximately $1.06 \mathrm{Nm}$ peak-to-peak. However, when $\mathrm{J}_{\mathrm{e}}$ is set to $15 \mathrm{~A} / \mathrm{mm}^{2}$, the induced voltage is slightly distorted and the amplitude is increased to $263.2 \mathrm{~V}$ which is more than double of that under no FEC current. This is due to the field strengthening effect by the additional FEC. For load analysis, performances of the machine at maximum $\mathrm{J}_{\mathrm{a}}$ and $\mathrm{J}_{\mathrm{e}}$ are analyzed. The torque and power obtained at base speed $5731.4 \mathrm{r} / \mathrm{min}$ are $175.9 \mathrm{Nm}$ and $105.6 \mathrm{~kW}$, respectively, which is less than the target value. To investigate this issue, the torque versus $J_{e}$ at various $J_{a}$ is plotted as depicted in Figure 5. It is obvious that the torque is increased with increasing $\mathrm{J}_{\mathrm{e}}$ up to certain $J_{e}$ and begins to decrease when higher $J_{e}$ is applied as shown in red circle. For instance, at $J_{a}$ of 30 $\mathrm{A}_{\mathrm{rms}} / \mathrm{mm}^{2}$, the maximum torque of $181.66 \mathrm{Nm}$ is obtained when $\mathrm{J}_{\mathrm{e}}$ is set to $20 \mathrm{~A} / \mathrm{mm}^{2}$. However, the torque starts to reduce when $\mathrm{J}_{\mathrm{e}}$ is set higher than this value. For $\mathrm{J}_{\mathrm{a}}$ of $20 \mathrm{~A}_{\mathrm{rms}} / \mathrm{mm}^{2}$ and $25 \mathrm{~A}_{\mathrm{rms}} / \mathrm{mm}^{2}$, the maximum torque obtained are $152.72 \mathrm{Nm}$ and $170.94 \mathrm{Nm}$ respectively, when $\mathrm{J}_{\mathrm{e}}$ is set to $15 \mathrm{~A} / \mathrm{mm}^{2}$. The torque also starts to reduce when $J_{e}$ is set higher than this value. Similarly, the same phenomenon occurs at the condition of $\mathrm{J}_{\mathrm{a}}$ of 5 $\mathrm{A}_{\mathrm{rms}} / \mathrm{mm}^{2}, 10 \mathrm{~A}_{\mathrm{rms}} / \mathrm{mm}^{2}$ and $15 \mathrm{~A}_{\mathrm{rms}} / \mathrm{mm}^{2}$ where the torque starts to reduce when $\mathrm{J}_{\mathrm{e}}$ is set higher than 10 $\mathrm{A} / \mathrm{mm}^{2}$.

To explain this phenomenon, further investigation is examined on the flux density distribution at three conditions 1) before maximum torque, 2) at maximum torque, and 3) after maximum torque. For example, at maximum $\mathrm{J}_{\mathrm{a}}$ of $30 \mathrm{~A}_{\mathrm{rms}} / \mathrm{mm}^{2}$, flux distribution at $\mathrm{J}_{\mathrm{e}}$ of $10 \mathrm{~A} / \mathrm{mm}^{2}, 20$ $\mathrm{A} / \mathrm{mm}^{2}$ and $30 \mathrm{~A} / \mathrm{mm}^{2}$ are investigated as shown in Figure 6. It can be seen that for low $\mathrm{J}_{\mathrm{e}}$ of $10 \mathrm{~A} / \mathrm{mm}^{2}$, the flux can easily flow to the direction according to its principle as shown in Figure 6(a). Nevertheless, the flux flow to the left part starts to saturate between armature coil upper slot and FEC lower slot marked in blue circle when $\mathrm{J}_{\mathrm{e}}$ is set to $20 \mathrm{~A} / \mathrm{mm}^{2}$ as shown in Figure 6(b). In this case, some of the flux from FEC which flow to the right side

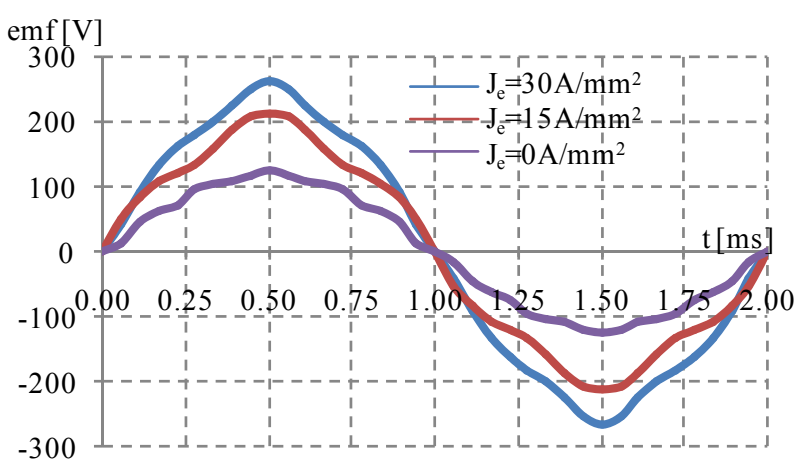

Figure 3. Back-emf at $3000 \mathrm{r} / \mathrm{min}$.

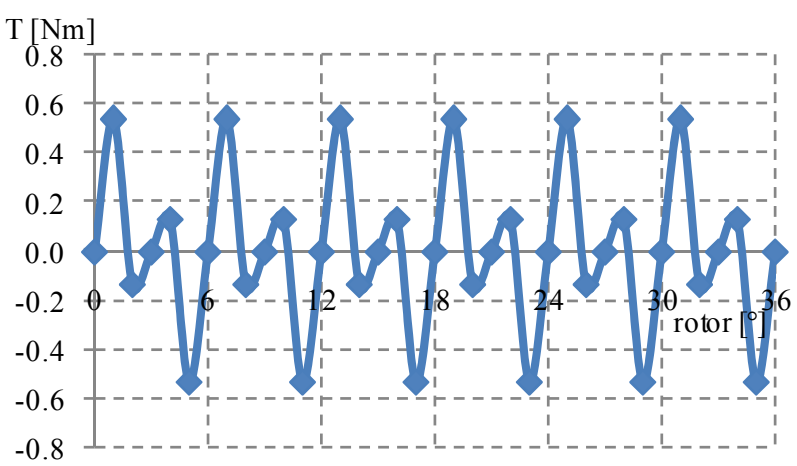

Figure 4. Cogging torque of the original design HEFSM.

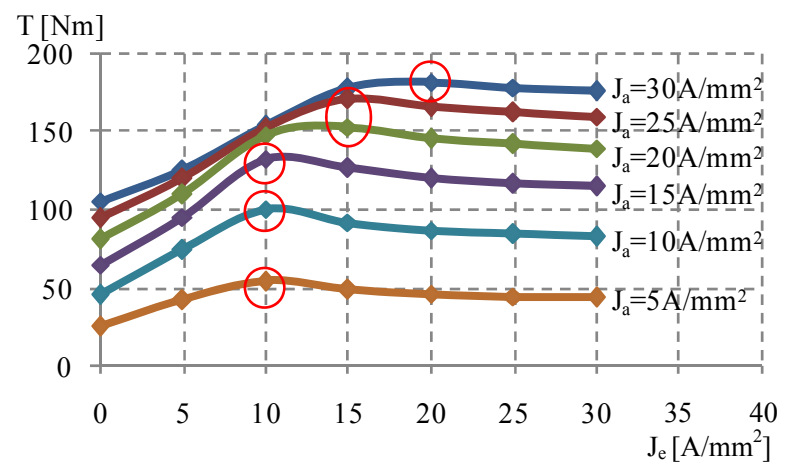

Figure 5. Torque versus $J_{e}$ at various $J_{a}$.

cancelled the flux from PM as shown in red circle which results in reducing the torque production. Hence, for the maximum $\mathrm{J}_{\mathrm{e}}$ of $30 \mathrm{~A} / \mathrm{mm}^{2}$ where much FEC flux is generated, the flux flow to the left part is totally saturated between armature coil upper slot and FEC lower slot marked in blue circle. Therefore, much higher flux from the stator outer yoke passes the FEC pitch move towards the PM in the right side. This flux also cancelled the PM flux and some of the flux is forces to flow into the rotor side producing much negative torque as shown in Figure 6(c), hence reducing the torque production. Thus, one of the methods that can be used to overcome this problem is by investigating the suitable length between armature coil upper slot and FEC lower slot to avoid flux saturation. 


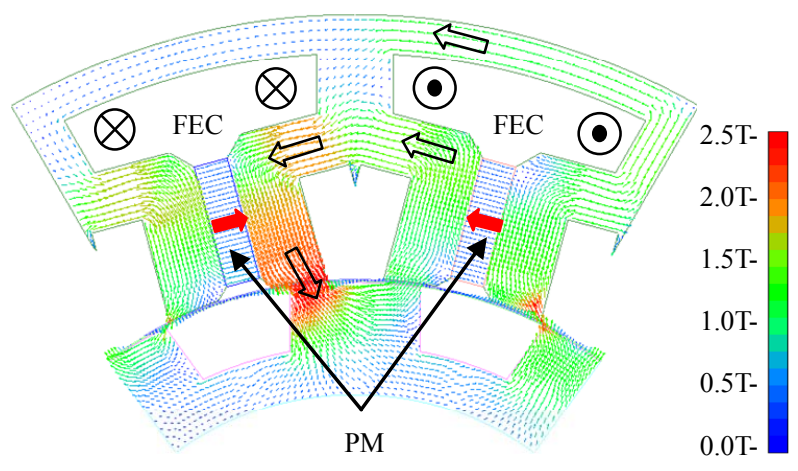

(a)

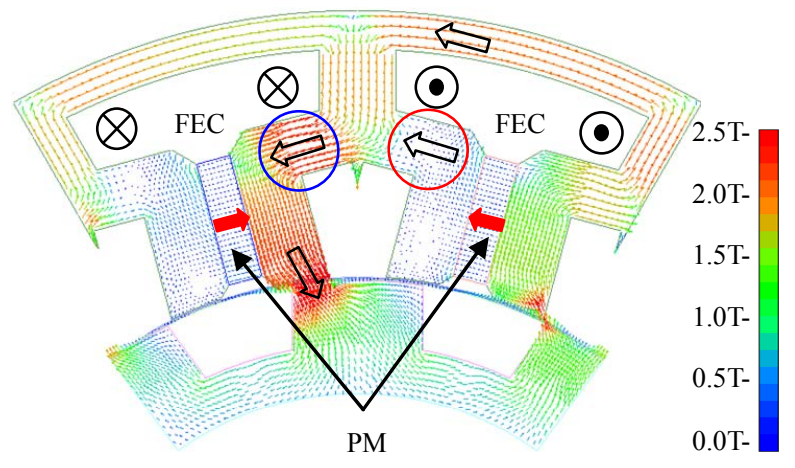

(b)

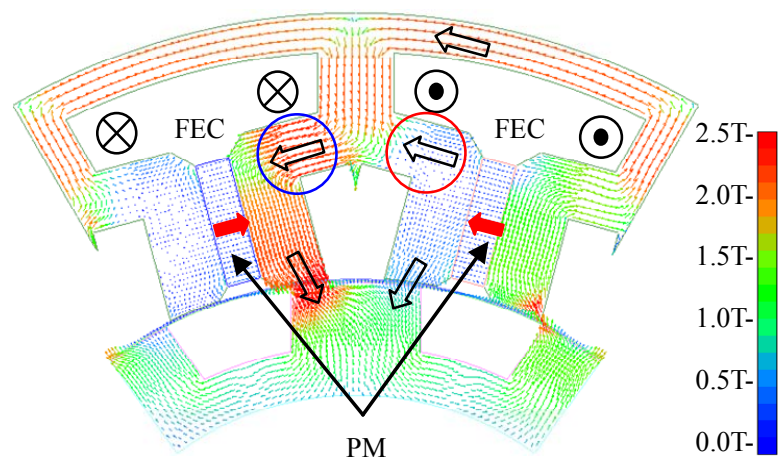

(c)

Figure 6. Flux vector diagram of various $J_{e}$ at maximum $J_{a}$ of $30 \mathrm{~A}_{\mathrm{rms}} / \mathrm{mm}^{2}$ (a) $\mathrm{J}_{\mathrm{e}}=10 \mathrm{~A} / \mathrm{mm}^{2}, T=153.4 \mathrm{Nm}$ (b) $\mathrm{J}_{\mathrm{e}}=20$ $\mathrm{A} / \mathrm{mm}^{2}, T_{\max }=181.7 \mathrm{Nm}$ (c) $J_{\mathrm{e}}=30 \mathrm{~A} / \mathrm{mm}^{2}, T=175.9 \mathrm{Nm}$.

\section{Design Methodology for Improvements}

To make a simple design, the shape of armature coil slot and air gap between the inner and outer PM are redesign, so that design free parameters of $D_{1}$ to $D_{10}$ can be defined as illustrated in Figure 7. The first step is carried out by updating the rotor parameters, $\mathrm{D}_{1}, \mathrm{D}_{2}$ and $\mathrm{D}_{3}$ while keeping $\mathrm{D}_{4}$ to $\mathrm{D}_{10}$ as constant. As the torque increases with the increase in rotor radius, $D_{1}$ which is considered as the dominant parameter that can improve the torque is firstly treated. In this condition, $\mathrm{D}_{4}, \mathrm{D}_{6}, \mathrm{D}_{8}, \mathrm{D}_{9}$ and $\mathrm{D}_{10}$ are simply shifted to the new position by following the movement of $\mathrm{D}_{1}$, while $\mathrm{D}_{5}$ and $\mathrm{D}_{7}$ are kept constant. Then, by selecting $\mathrm{D}_{1}$ at its maximum performance, both rotor pole width $\mathrm{D}_{2}$ and rotor pole depth $\mathrm{D}_{3}$ are varied. Once the maximum performance from the combination of $\mathrm{D}_{2}$ and $\mathrm{D}_{3}$ is determined, the second step is carried out by changing the FEC slot parameters $\mathrm{D}_{4}, \mathrm{D}_{5}$ and $\mathrm{D}_{6}$ while keeping the other parameters constant. Then, by using the combination of $\mathrm{D}_{4}$ to $\mathrm{D}_{6}$ that bring out the maximum performance at the second step, the third step is carried out by varying the armature coil slot parameters $\mathrm{D}_{7}$ and $\mathrm{D}_{8}$ with keeping other parameters constant. The necessary armature coil slot area, $\mathrm{S}_{\mathrm{a}}$ is determined by varying armature coil depth, $\mathrm{D}_{7}$ and armature coil width, $\mathrm{D}_{8}$ to accommodate natural number of turns, $\mathrm{N}_{\mathrm{a}}$ for armature coil. Furthermore, to ensure the PM is not demagnetized at temperatures as high as $180^{\circ} \mathrm{C}, \mathrm{D}_{9}$ and $\mathrm{D}_{10}$ are adjusted with keeping the same PM volume. The method of changing $D_{1}$ to $D_{10}$ is treated repeatedly until the target performances are achieved.

All design parameters are adjusted with keeping air gap length of $0.8 \mathrm{~mm}$ constant under maximum $\mathrm{J}_{\mathrm{a}}$ and $\mathrm{J}_{\mathrm{e}}$. In addition, at the final design, the corners circled in Figure 7 are designed as a curve to ensure all flux at the edge of the shape flow more smoothly, hence increases the performance of the machine. For the rotor inner pole, the curve designed not only increased the flux flows but also increase the rotor mechanical strength of the machine, make it more robust to work in high speed condition. Finally, after few cycle of optimization, the machine satisfied the target requirements and performances for HEV applications. The cross sectional views of the final design HEFSM is depicted in Figure 8, while details of final parameters are listed in Table 2. The differences between the initial and the final design HEFSM are 1)

Table 2. Initial and final design parameters.

\begin{tabular}{cccc}
\hline & Details & Initial & Final \\
\cline { 2 - 4 } & PM volume $(\mathrm{kg})$ & 1.1 & 1.1 \\
\hline $\mathrm{D}_{1}$ & Rotor radius $(\mathrm{mm})$ & 80.2 & 88.2 \\
$\mathrm{D}_{2}$ & Rotor pole width $(\mathrm{mm})$ & 12.5 & 9.5 \\
$\mathrm{D}_{3}$ & Rotor pole depth $(\mathrm{mm})$ & 12.2 & 23.2 \\
$\mathrm{D}_{4}$ & Permanent magnet height $(\mathrm{mm})$ & 24.0 & 15.0 \\
$\mathrm{D}_{5}$ & FEC slot pitch (mm) & 7.4 & 20.0 \\
$\mathrm{D}_{6}$ & Stator outer core thickness (mm) & 7.4 & 8.0 \\
$\mathrm{D}_{7}$ & Armature coil width (mm) & 8.0 & 6.0 \\
$\mathrm{D}_{8}$ & Armature coil depth (mm) & 19.1 & 32.71 \\
$\mathrm{D}_{9}$ & Distance between air gap and PM (mm) & 2.0 & 0.5 \\
$\mathrm{D}_{10}$ & Distance between FEC and PM (mm) & 4.0 & 0.5 \\
$\mathrm{~N}_{\mathrm{a}}$ & No. of turns of armature coil & 7 & 9 \\
$\mathrm{~T}$ & Torque (Nm) & 175.86 & 334.5 \\
$\mathrm{~N}$ & Speed (r/min) & 5731.4 & 3701.2 \\
$\mathrm{P}$ & Power (kW) & 105.55 & 129.6 \\
$\mathrm{pf}$ & Power factor & 0.368 & 0.452 \\
\hline
\end{tabular}




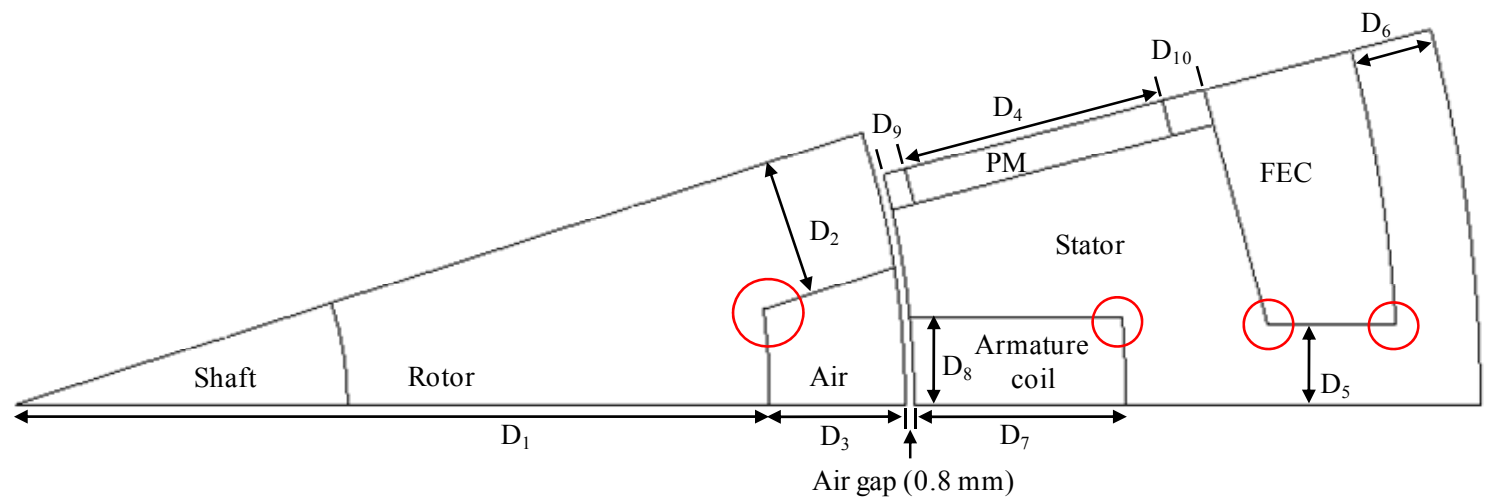

Figure 7. Design parameter defined as $D_{1}$ to $D_{10}$.

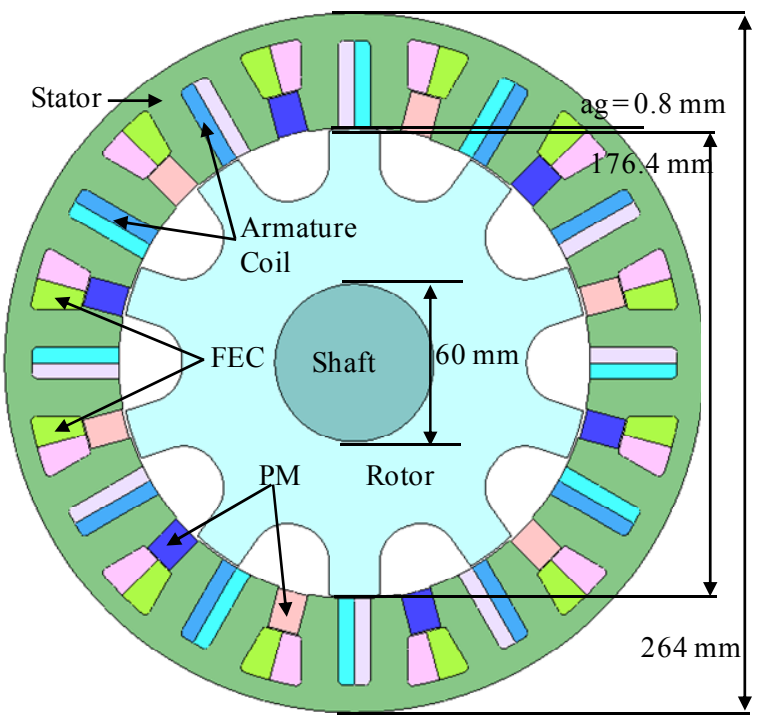

Figure 8. Final Design HEFSM.

the rotor radius of the final design is longer than the initial rotor radius which gives more torque as had been expected, 2) the armature coil width of the final design is less than the initial design, but has high armature coil depth which results in more number of turns, 3 ) the FEC slot area is reduced approximately $40 \%$ from the initial design to cover some volume of stator yoke used for armature coil, 4) the final design has less PM depth with high PM width to keep the same PM volume of $1.1 \mathrm{~kg}, 5$ ) the final design has no gap between armature coil upper slot and FEC lower slot which solved the flux saturation problem, 6) the stator outer core thickness is higher than the initial design to allow more flux to flow smoothly, and 7) the final design has a stator yoke with a straight "I shape" that makes the flux flow more easily into the rotor. As a proof, Figure 9 illustrates the flux distribution of the final design HEFSM for $\mathrm{J}_{\mathrm{e}}$ of $20 \mathrm{~A} / \mathrm{mm}^{2}$ and 30 $\mathrm{A} / \mathrm{mm}^{2}$ with maximum $\mathrm{J}_{\mathrm{a}}$ of $30 \mathrm{~A}_{\mathrm{rms}} / \mathrm{mm}^{2}$. As the gap between armature coil upper slot and FEC lower slot in the final design HEFSM is expanded and considered

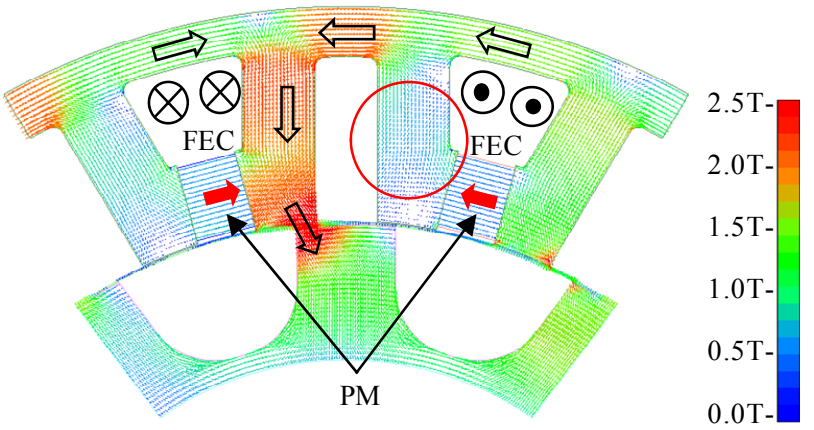

(a)

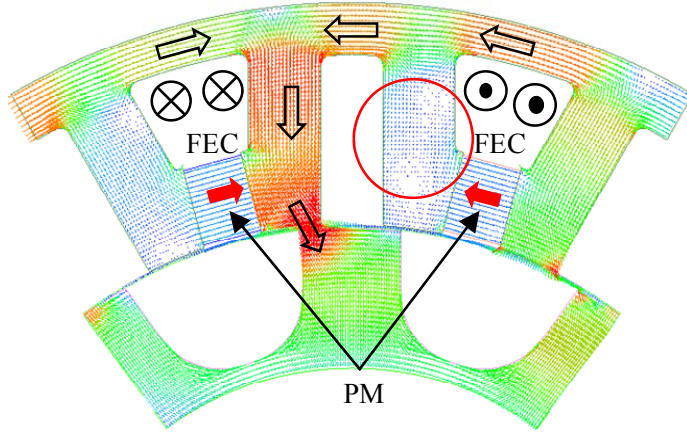

$2.5 \mathrm{~T}-$
$2.0 \mathrm{~T}-$
$1.5 \mathrm{~T}-$
$1.0 \mathrm{~T}-$
$0.5 \mathrm{~T}-$
$0.0 \mathrm{~T}-$

(b)

Figure 9. Flux vector diagram of various $J_{e}$ at maximum $J_{a}$ of $30 \mathrm{~A}_{\mathrm{rms}} / \mathrm{mm}^{2}$ (a) $J_{\mathrm{e}}=20 \mathrm{~A} / \mathrm{mm}^{2}, T=280.4 \mathrm{Nm}$ (b) $J_{\mathrm{e}}=30$ $\mathrm{A} / \mathrm{mm}^{2}, \mathrm{~T}=334.4 \mathrm{Nm}$.

negligible, the magnetic saturation caused by higher FEC current is relaxed. Thus, the improved design maintains the same torque for both current density conditions and enables to extract higher power factor.

\section{Results and Performances of the Final Design HEFSM}

\subsection{Flux Path at Open Circuit Condition}

The open circuit field distribution for PM and FEC of the final design HEFSM are investigated based on 2D-FEA as illustrated in Figure 10. Figure 10(a) illustrates the 
flux path due to mmf of PM only, while Figure 10(b) represents the combination of flux line from both PM and mmf of FEC at maximum FEC density, $\mathrm{J}_{\mathrm{e}}$ of $30 \mathrm{~A} / \mathrm{mm}^{2}$. In Figure 10(a), it is obvious that almost $100 \%$ flux of PM flow in the stator iron around the FEC. This yields negligible cogging torque and almost no back-emf at open-circuit condition under the maximum speed operation, which makes it easy to protect the switching devices when the inverter is shut down due to some failures. In contrast, from Figure 10(b), a large amount of fluxes flow to the rotor side by field strengthening excitation, resulting in the maximum torque production with the aid of hybrid excitation.

Furthermore, Figures 11 and 12 illustrate the comparison between back-emf and cogging torque of the initial and final design at $3000 \mathrm{r} / \mathrm{min}$, respectively. It is clear that, the back emf of the final design is more sinusoidal and much less by approximately $36 \%$ of the initial design. The final cogging torque is also reduced by more than $50 \%$ of the initial design.

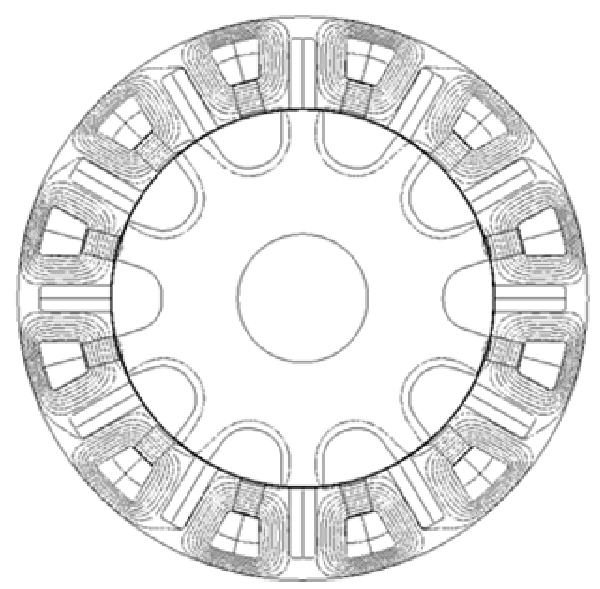

(a)

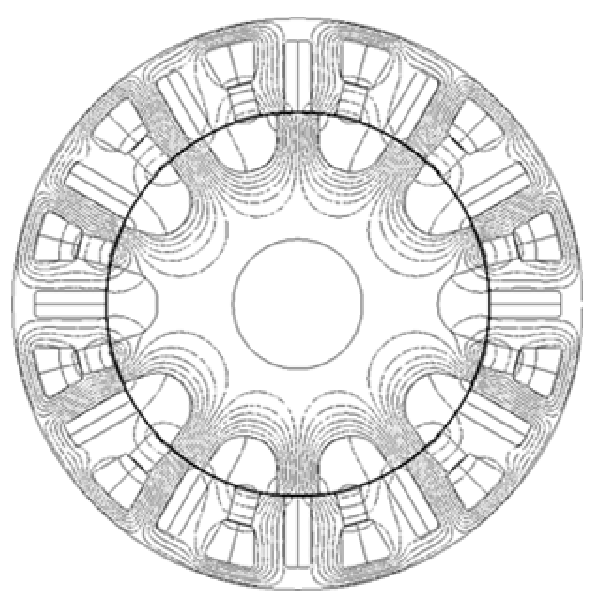

(b)

Figure 10. Flux path of the final design HEFSM at open circuit condition (a) PM only (b) PM and maximum FEC current density of $30 \mathrm{~A} / \mathrm{mm}^{2}$.

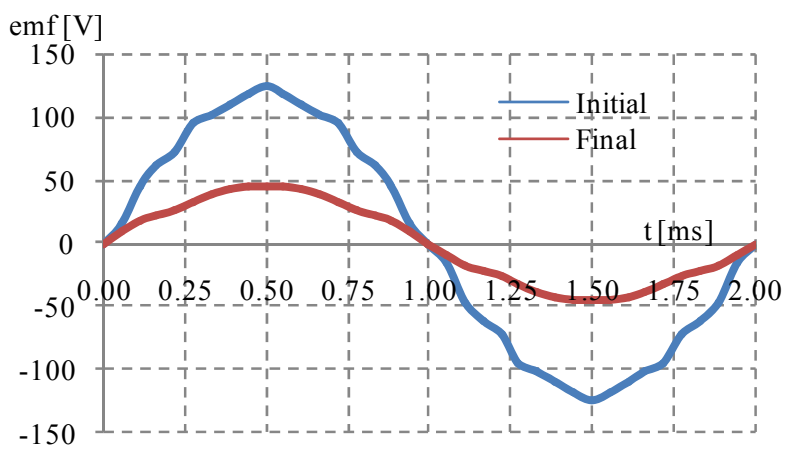

Figure 11. Back-emf.

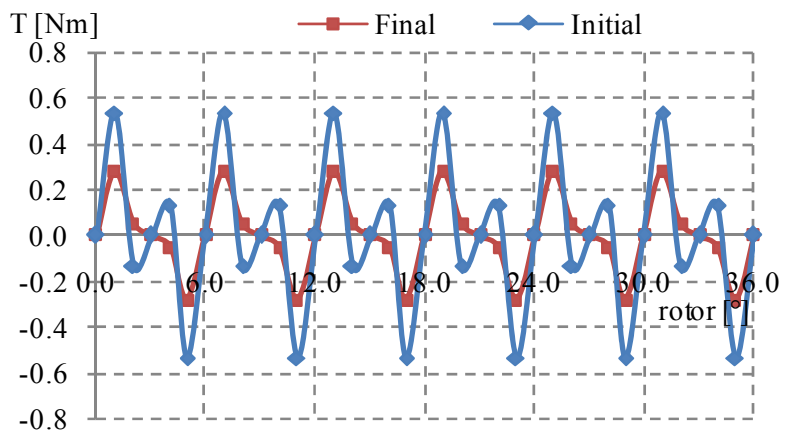

Figure 12. Cogging torque.

\subsection{Torque and Power Factor versus $J_{e}$ Characteristics}

The torque and power factor versus $\mathrm{J}_{\mathrm{e}}$ characteristics are plotted in Figures 13 and 14, respectively. From the plot, it is obvious that increasing $\mathrm{J}_{\mathrm{a}}$ will increase the torque but will reduce the power factor. To equilibrate this situation, $\mathrm{J}_{\mathrm{e}}$ is increased so that the power factor can be improved and kept constant even if $\mathrm{J}_{\mathrm{a}}$ is very high. The plots clearly show that maximum torque of $334.4 \mathrm{NM}$ is obtained when $\mathrm{J}_{\mathrm{a}}$ and $\mathrm{J}_{\mathrm{e}}$ are set to $30 \mathrm{~A} / \mathrm{mm}^{2}$ as their maximum with the power factor of 0.452 . However, for low $\mathrm{J}_{\mathrm{a}}$ of less than $15 \mathrm{~A}_{\mathrm{rms}} / \mathrm{mm}^{2}$, the torque are slightly reduced with the increasing of $\mathrm{J}_{\mathrm{e}}$ of more than $20 \mathrm{~A} / \mathrm{mm}^{2}$. This situation occurs due to excessive FEC flux that generates negative torque thus reducing the performances, similar with the original HEFSM discussed previously. The comparison between the torque and power factor versus $\mathrm{J}_{\mathrm{e}}$ under maximum $\mathrm{J}_{\mathrm{a}}$ for the initial and final design HEFSM is depicted Figure 15. The torque and power factor of the final design HEFSM increased approximately $50 \%$ and $23 \%$, respectively compared with the original design.

\subsection{Torque and Power versus Speed Characteristics}

The torque versus speed characteristics of the IPMSM and the final design HEFSM are plotted in Figure 16. 


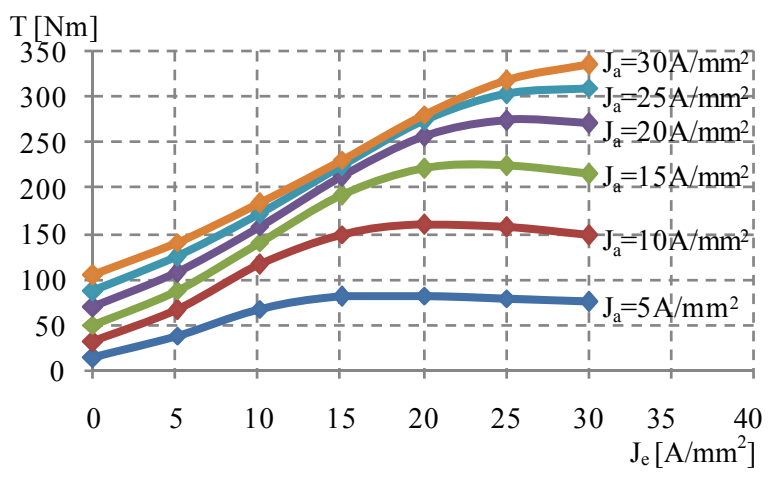

Figure 13. Torque vs $\mathbf{J}_{\mathbf{e}}$.

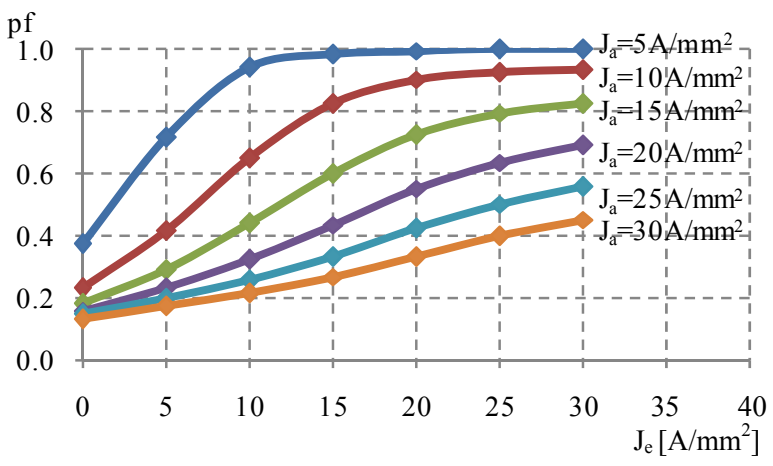

Figure 14. Power factor vs $\mathbf{J}_{\mathrm{e}}$.

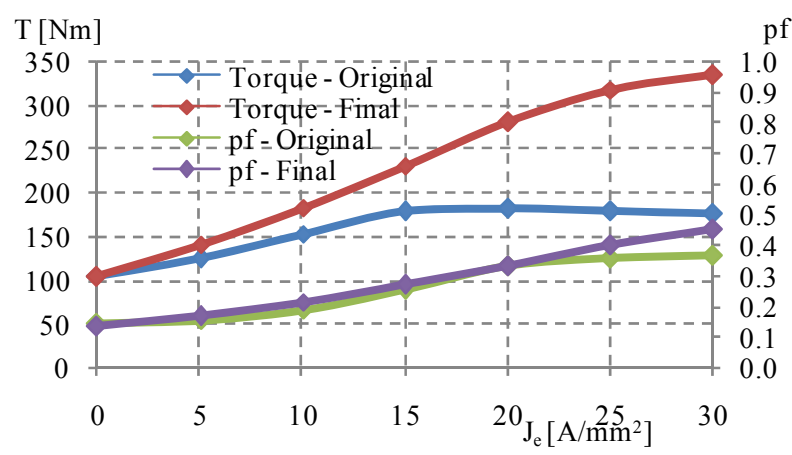

Figure 15. Torque and power factor vs $\mathbf{J}_{\mathrm{e}}$.

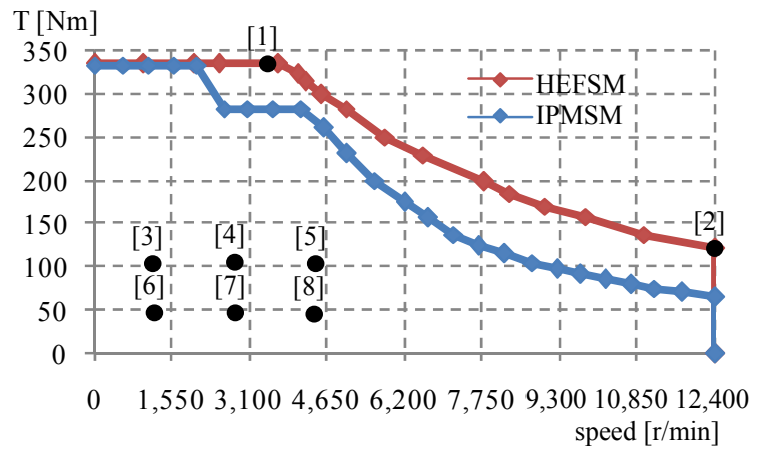

Figure 16. Torque vs speed characteristics.

The maximum torque obtained for IPMSM and HEFSM are $333 \mathrm{Nm}$ and $334.4 \mathrm{Nm}$, respectively. It is obvious that the HEFSM has better torque condition and produced much higher torque capability in high speed region. Meanwhile, Figure 17 illustrates the power versus speed characteristics of the IPMSM and the final design HEFSM. From the graph, 1) at maximum torque, the power achieved for IPMSM and the final design HEFSM is $72.1 \mathrm{~kW}$ and $129.6 \mathrm{~kW}$, at the speed of approximately $2100 \mathrm{r} / \mathrm{min}$ and $3701 \mathrm{r} / \mathrm{min}$, respectively, 2) the maximum power obtained is $123 \mathrm{~kW}$ for IPMSM and 162.8 $\mathrm{kW}$ for HEFSM 3 ) the average power of the IPMSM and the HEFSM at normal driving mode of $3000-6000 \mathrm{r} / \mathrm{min}$ are $113.7 \mathrm{~kW}$ and $133.7 \mathrm{~kW}$, respectively, which proves that the HEFSM has better performance than IPMSM in frequent driving condition. The total weight of the final design HEFSM including stator iron, rotor iron, PM, armature coil, FEC, and estimation of both coil ends is 29.3 $\mathrm{kg}$, which is $16.2 \%$ less than the estimated of $35 \mathrm{~kg}$ for IPMSM. Thus, the maximum torque density and maximum power density are $11.41 \mathrm{Nm} / \mathrm{kg}$ and $5.55 \mathrm{~kW} / \mathrm{kg}$, respectively, which is much higher than the target requirements for HEV applications. The maximum torque and power density of the final design HEFSM are increased approximately by $20.0 \%$ and $36.9 \%$, respectively compared to $9.51 \mathrm{Nm} / \mathrm{kg}$ and $3.51 \mathrm{~kW} / \mathrm{kg}$ of existing IPMSM.

\subsection{Motor Loss and Efficiency}

The motor loss and efficiency are calculated considering iron losses in all laminated cores, and copper losses in armature coil and FEC. The detailed loss and motor efficiency of the final design HEFSM at maximum torque, maximum power, and frequent operating point under light load driving condition noted as No. 1 to No. 8 in Figure 16 are illustrated in Figure 18. At high torque operating points No. 1, the efficiency is slightly degraded due to increase in copper loss while at high-speed operating point No. 2, the motor efficiency is degraded due to increase in iron loss. Furthermore, at frequent driving operation No. 3 to No. 8 under low load condition, the proposed machine achieves relatively high efficiency of more than $93 \%$.

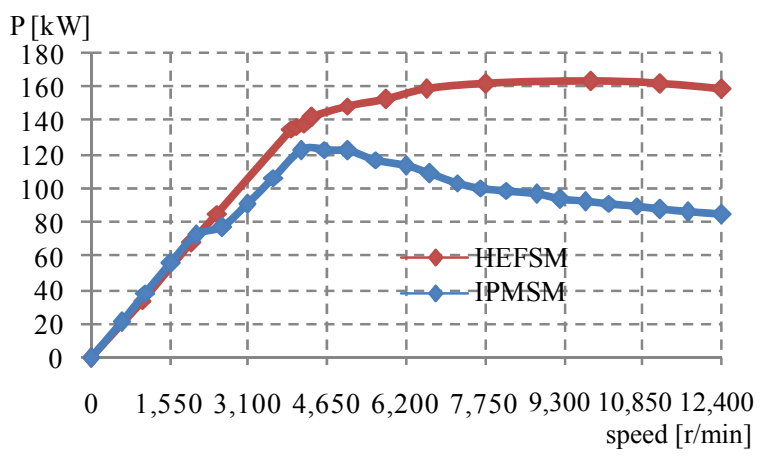

Figure 17. Power versus speed characteristics. 


\subsection{Rotor Mechanical Strength}

The mechanical stress prediction of rotor structure is calculated by centrifugal force analysis based on 2DFEA as depicted in Figure 19. The maximum stress at $12,400 \mathrm{r} / \mathrm{min}$ reaches $46 \mathrm{MPa}$ and $28 \mathrm{MPa}$ for the originnal and final design, respectively, which is much smaller than allowable maximum stress of $300 \mathrm{MPa}$ in conventional electromagnetic steel. This is a great advantage of the final design HEFSM that makes it more applicable and suitable to operate in high-speed application compare to conventional IPMSM.

\section{Conclusion}

In this paper, design feasibility studies and performance analysis of 12Slot-10Pole HEFSM for traction drive in the target HEV have been presented. The design refinement has been clearly demonstrated and finally achieved

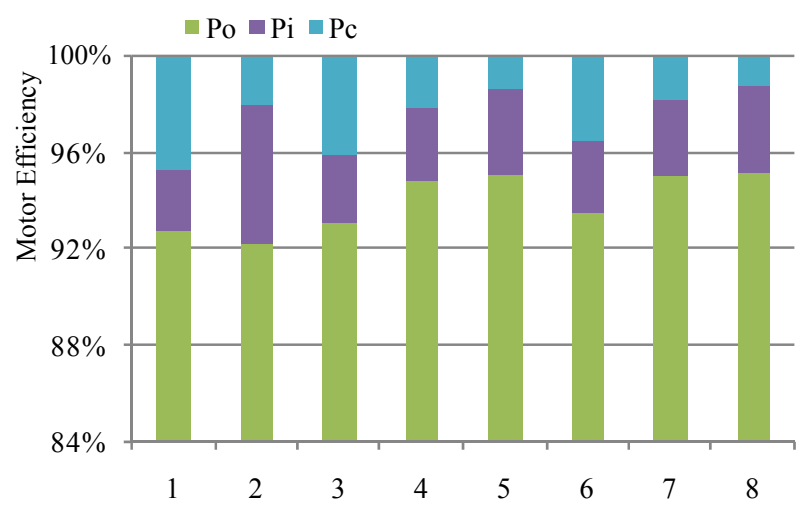

Figure 18. Motor efficiency.

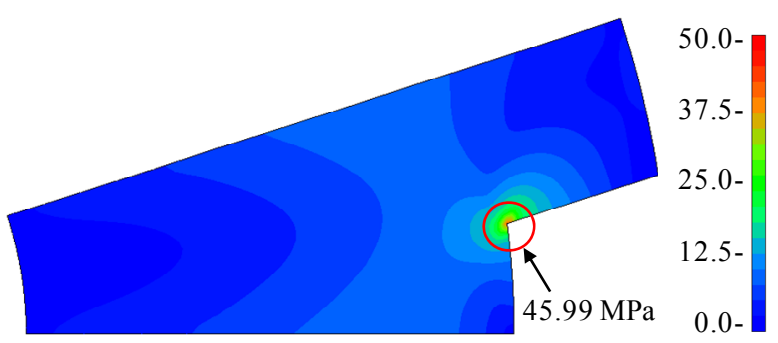

(a)

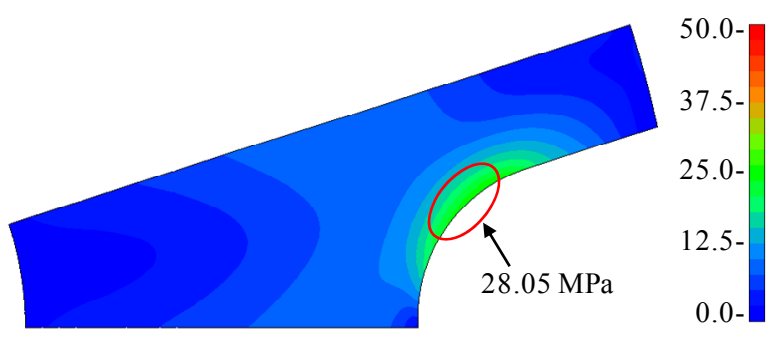

(b)

Figure 19. Principal stress distributions of rotor at $\mathbf{1 2 , 4 0 0}$ $\mathbf{r} / \mathbf{m i n}$ (a) initial design (b) final design. the target performances. In addition, the rotor mechanical stress predicted is good enough for the machine to run in high-speed region. Finally, the power density of the final design HEFSM has been increased of more than one third when compared with existing IPMSM for LEXUS $\mathrm{RX} 400 \mathrm{~h}$. As conclusion, the goal of this research to get maximum performances for HEV applications has been successfully achieved.

\section{REFERENCES}

[1] X. G. Luo and T. A. Lipo, "A Synchronous/Permanent Magnet Hybrid AC Machine," IEEE Transactions on Energy Conversion, Vol. 15, No. 2, 2000, pp. 203-210. doi:10.1109/60.867001

[2] N. Naoe and T. Fukami, "Trial Production of a Hybrid Excitation Type Synchronous Machine," Proceedings of IEEE International Electric Machines and Drives Conference, Cambridge, 17-20 June 2001, pp. 545-547. doi:10.1109/IEMDC.2001.939362

[3] D. Fodorean, A. Djerdir, I. A. Viorel and A. Miraoui, “A Double Excited Synchronous Machine for Direct Drive Application-Design and Prototype Tests," IEEE Transactions on Energy Conversion, Vol. 22, No. 3, 2007, pp. 656-665. doi:10.1109/TEC.2007.896279

[4] J. A. Tapia, F. Leonardi and T. A. Lipo, "ConsequentPole Permanent-Magnet Machine with Extended FieldWeakening Capability," IEEE Transactions on Industry Applications, Vol. 39, No. 6, 2003, pp. 1704-1709. doi:10.1109/TIA.2003.818993

[5] T. Kosaka and N. Matsui, "Hybrid Excitation Machines with Powdered Iron Core for Electrical Traction Drive Applications," Proceedings of International Conference on Electrical Machines and Systems, Wuhan, China, 17-20 October 2008, pp. 2974-979.

[6] T. Kosaka, M. Sridharbabu, M. Yamamoto and N. Matsui, "Design Studies of Hybrid Excitation Motor for Main Spindle Drive in Machine Tools," IEEE Transactions on Industrial Electronics, Vol. 57, No. 11, 2010, pp. 38073813. doi:10.1109/TIE.2010.2040560

[7] Z. Chen, Y. Sun and Y. Yan, "Static Characteristics of A Novel Hybrid Excitation Doubly Salient Machine," Proceedings of the Eight International Conference on Electrical Machines and Systems, Nanjing, 27-29 September 2005, pp. 718-721.

[8] K. T. Chau, J. Z. Jiang and W. Yong, "A Novel Stator Doubly Fed Doubly Salient Permanent Magnet Brushless Machine," IEEE Transactions on Magnetics, Vol. 39, No. 5, 2003, pp. 3001-3003. doi:10.1109/TMAG.2003.816722

[9] Y. Amara, L. Vido, M. Gabsi, E. Hoang, A. H. Ben Ahmed and M. Lecrivain, "Hybrid Excitation Synchronous Machines: Energy-Efficient Solution for Vehicles Propulsion," IEEE Transactions on Vehicular Technology, Vol. 58, No. 5, 2009, pp. 2137-2149. doi:10.1109/TVT.2008.2009306

[10] D. Fodorean, A. Djerdir, I. A. Viorel and A. Miraoui, “A Double Excited Synchronous Machine for Direct Drive 
Application-Design and Prototype Tests," IEEE Transactions on Energy Conversion, Vol. 22, No. 3, 2007, pp. 656-665. doi:10.1109/TEC.2007.896279

[11] E. Sulaiman, T. Kosaka and N. Matsui, "Design Improvement and Performance Analysis of 12S-10P Permanent Magnet Flux Switching Machine with Field Excitation Coil," Journal of Electrical System, Vol. 8, No. 4, 2012, pp. 425-432. doi:10.1109/TIA.2003.818993

[12] H. Wei, M. Cheng and G. Zhang, "A Novel Hybrid Excitation Flux-Switching Motor for Hybrid Vehicles," IEEE Transactions on Magnetics, Vol. 45, No. 10, 2009, pp. 4728-4731. doi:10.1109/TMAG.2009.2022497

[13] E. Hoang, M. Lecrivain and M. Gabsi, "A New Structure of a Switching Flux Synchronous Polyphased Machine with Hybrid Excitation," Proceedings of European Conference on Power Electronics and Applications, Aalborg, 2-5 September 2007, pp. 1-8. doi:10.1109/EPE.2007.4417204
[14] E. Sulaiman, T. Kosaka and N. Matsui, "Design Optimization and Performance of A Novel 6-Slot 5-Pole PMFSM with Hybrid Excitation for Hybrid Electric Vehicle," IEEJ Transactions on Industry Applications, Vol. 132, No. 2, 2011, pp. 211-218.

[15] A. Zulu, B. C. Mecrow and M. Armstrong, "A Wound-Field Three-Phase Flux-Switching Synchronous Motor with All Excitation Sources on The Stator," IEEE Transactions on Industry Applications, Vol. 46, No. 6, 2010, pp. 2363-2371. doi:10.1109/TIA.2010.2072972

[16] E. Sulaiman, T. Kosaka and N. Matsui, "High Power Density Design of 6Slot-8Pole Hybrid Excitation Flux Switching Machine for Hybrid Electric Vehicle," IEEE Transactions on Magnetics, Vol. 47, No. 10, 2011 pp. 4453-4456. doi:10.1109/TMAG.2011.2140315

[17] M. Kamiya, "Development of Traction Drive Motors for the Toyota Hybrid Systems," IEEJ Transactions on Industry Applications, Vol. 126, No. 4, 2006, pp. 473-479. 